\title{
Discursos das missões cristãs atuais: Análise textual a partir dos textos bíblicos
}

A partir das missões religiosas má-compreendidas surgem as intolerâncias religiosas. Com os vários expoentes da fundamentação de teologia da missão, os ensinamentos de Jesus Cristo são transmitidos de diversas formas; os comportamentos dos cristãos entre as próprias comunidades cristãs mostram uma pluralidade de ideias de teologia da missão. Entre os próprios cristãos há conflitos para definir quais missões religiosas seguem os ensinamentos de Jesus Cristo. A lógica cristã demonstra um conjunto de ideias para o bem comum de todos, muitas vezes estas ideias são intensificadas pelos discursos missionários religiosos, outras vezes são ideologias religiosas de dominação que oprimem outras culturas. Então, através do entendimento lógico dos discursos missionários religiosos, em específico do Cristianismo, reflete quais discursos se aproximam dos ensinamentos de Jesus Cristo transcritos nos textos bíblicos. $O$ trabalho é um estudo sistemático com os principais expoentes teóricos de Teologia da Missão em todo contexto da globalização atual; são analisados os estudos dos textos bíblicos aplicados na atualidade, em correlação se reflete sobre os textos bíblicos e suas ideias universalizadas já consolidadas na cultura global. Os principais materiais científicos são livros coletâneas que explicam parcialmente todos os discursos das missões religiosas sobre a ótica dos ensinamentos dos textos bíblicos. Através dos discursos missionários religiosos transmitidos pelos expoentes teóricos da teologia da missão, reflete-se: As missões atuais condizem com os ensinamentos bíblicos? Quais são as missões que se aproximam da divindade de Jesus Cristo relatada na Bíblia? O que são as missões cristãs para o contexto da globalização?.

Palavras-chave: Discursos missionários religiosos; Teologia da missão; Textos bíblicos; Jesus Cristo.

\section{Speeches of Christian missions current: Textual analysis from biblical texts}

\begin{abstract}
Missions of misunderstood religious arise religious intolerance. The various exponents of the foundation of mission theology, the teachings of Jesus Christ, are transmitted in various ways; Christian behavior among Christian communities themselves shows a plurality of ideas from mission theology. Among Christians, themselves there are conflicts to define which religious missions follow the teachings of Jesus Christ. Christian logic demonstrates a set of ideas for good with all, often these ideas are intensified by religious missionary discourses, sometimes they are religious ideologies of domination that oppress other cultures. Then, through the logical understanding of religious missionary discourses, specifically Christianity, reflects which discourses come close to the teachings of Jesus Christ transcribed in the biblical texts. The work is a systematic study with the main theoretical exponents of Mission Theology in every context of current globalization; the studies of the biblical texts applied today analyzed, in correlation is reflected on the biblical texts and their universalized ideas already consolidated in the global culture. The main scientific materials are collection books that partially explain all the discourses of religious missions on the optics of the teachings of biblical texts. Through the religious missionary discourses transmitted by the theoretical exponents of mission theology, it is reflected: Do the present missions fit the biblical teachings? What are the missions that approach the divinity of Jesus Christ reported in the Bible? What are Christian missions for the context of globalization?.
\end{abstract}

Keywords: Religious missionary speeches; Mission theology; Biblical texts; Jesus Christ.

Topic: Tradições e Escrituras Sagradas

Reviewed anonymously in the process of blind peer.
Received: $11 / 12 / 2019$

Approved: 20/03/2020
Naccer Cayc Ribeiro Donato (iD

Centro Universitário Internacional, Brasil http://lattes.cnpq.br/4285077522771135 http://orcid.org/0000-0001-8162-1009

naccercaycrd@gmail.com

Sandra Morais Ribeiro Dos Santos (in)

Universidade Católica do Paraná, Brasil

http://lattes.cnpq.br/2210608598733509

http://orcid.org/0000-0001-9889-0264

naccercaycrd@gmail.com
Referencing this:

DONATO, N. C. R.; SANTOS, S. M. R.. Discursos das missões cristãs atuais: Análise textual a partir dos textos bíblicos. Social Evolution, v.4, n.1, p.1-9, 2020. DOI: http://doi.org/10.6008/CBPC2595430X.2020.001.0001 


\section{INTRODUÇÃO}

O trabalho investigará se as concepções missionárias estão condizentes as ideias do viver de acordo com a natureza bíblica e sua Teologia cristã. Hoje o que acontece são os aumentos das diversas linhas de pensamentos cristãs, com isto, de acordo com o senso comum o que é mais debatido entre os Teólogos, os Cientistas sociais e os Líderes Religiosos são as 'intolerâncias religiosas', fortes ainda no século XXI, mesmo com muitos missionários e com o desenvolvimento significativo da Teologia da Missão.

$\mathrm{Na}$ atualidade as ideias das missões cristãs se desenvolvem de acordo com as tarefas das Escrituras Sagradas?. De acordo com Ratzinger (2008), a investigação desta indagação surge da ideia da formação da Igreja como corpo maior do Cristianismo. Já as doutrinas criadas a partir das tradições cristãs e das Escrituras Sagradas não se formariam, ou, não se estruturariam sem a união de crenças diversas e pluralistas. O que as ideias missionárias cristãs fazem para o bem comum atualmente?. Esta parece ser a pergunta-chave para o entendimento do todo da Teologia da Missão e da aplicação dos ensinamentos da Bíblia.

Este Artigo tem por objeto realizar um estudo sistemático, reflexivo e analítico, das atualizações e das ideias missionárias transculturais cristãs na contemporaneidade, associada aos textos bíblicos. As especificidades objetivadas são: primeiro através de estudos atuais relacionados as lógicas: da Fé; dos atores sociais e políticos; dos missionários das Igrejas Cristãs. No segundo momento, comparar as ideias teológicas missionárias e as ideias políticas aplicadas na atualidade, para perceber suas similaridades e seus desafios em confronto dos problemas sociais. Por último, propor ideias devocionais, motivacionais e multidisciplinares para os religiosos e os atores sociais, que se inserem no Cristianismo, esses necessitam urgentemente trazer a aplicabilidade dos ensinamentos de Jesus Cristo para as condições humanas do século $\mathrm{XXI}$, de forma interativa com todos e não divididos e isolados em cada comunidade cristã.

Hoje todos no senso comum dizem que 'Jesus Cristo precisa voltar', entretanto não adquirem os ensinamentos dele revelados por Deus para aplicarem nas lógicas comuns de desenvolvimento empresarial e organizacional. O que é analisado são hipóteses e o comportamento social global, em contextos dos discursos religiosos, cada vez mais diversificados; sobre o comparativo dos textos bíblicos. Já o que se adquire de concreto são os documentos das mídias sociais, que nota as temáticas em alta dos discursos são: 'crises'; 'pobrezas'; 'curas e milagres'; entre outros temas em geral catastrófico; esses já consolidado no senso comum, principalmente no desenvolvimento do cristianismo e de suas missões.

\section{METODOLOGIA}

No que diz respeito aos acontecimentos serão consideradas todas as análises teológicas acadêmicas possíveis, descritas através da lógica da teologia da Missão, essas como um conjunto de estudos dentro da Teologia Cristã. Segundo Emediato et al. (2017), são discursos midiáticos os mais relevantes das Igrejas cristãs, sendo eles mídias digitais ou mídias impressas; em geral a sua descoberta é que os discursos atuais religiosos se correlacionam aos princípios e virtudes religiosas, são estas exemplificadas como: "solidariedade"; "fidelidade"; "lealdade"; além de como argumentos divinos, a "vocalidade", a "verdade" e a 
"justiça".

A eficiência do discurso das instituições, suas estratégias de comunicação e sua força de convencimento são elementos que ajudarão a formar a cognição social. No caso do discurso religioso, no entanto, a força maior está nos próprios fundamentos religiosos, sagrados ou relevantes para os fiéis, que servem como fonte normatizadora dos comportamentos e das crenças suscetíveis de circular em diferentes formas e práticas sociais, o que ressalta o valor constituinte - e fundador - do discurso religioso. No entanto, as pessoas, mesmo sendo fiéis às suas igrejas, não vivem apenas uma experiência religiosa no mundo. Elas trabalham, sofrem restrições nas relações de trabalho e de consumo, são desafiadas continuamente no mundo social para além da vida religiosa que podem ter. Amam, odeiam, pecam, são bons e maus, são humanos. A igreja procura exercer a sua influência, sem se desprender da realidade social onde vivem os seus adeptos, pois a sociedade moderna, como percebeu Durkheim e outros, não é mais a sociedade da idade média em que a religião gozava de certa centralidade. (EMEDIATO et al., 2017)

Os discursos religiosos, como todos teólogos sabem, são transformadores da realidade social, entretanto estão sob seu domínio. Como garantir que o missionário segue fielmente a doutrina cristã, sem desviar dos ensinamentos de Jesus Cristo?. Segundo Ratzinger (2008), a Fé, os pensamentos filosóficos e as ideias teológicas estão em constantes relacionamentos; o que se apresenta como verdade em comum dos três saberes é a construção do "homo christianus"; assim o cristianismo como verdadeira filosofia de vida precisa seguir o "Logos" de Jesus Cristo, pelo menos em suas tarefas.

De acordo com Padilla (1998), principal representante das bases teóricas da Teologia da missão no presente trabalho, os diversos estudos bíblicos, principalmente sobre os Livros Proféticos (Antigo Testamento) e os Evangelhos (Novo Testamento) trazem a missão como características do agir do Espírito Santo sobre os vários Povos da Terra, exemplos claros das missões de Jesus para todos que desejam realizar missões para Deus é o que transmite os Evangelhos de Lucas e de João. Ainda segundo Padilla (1998), o Evangelho de Lucas transmite a necessidade dos seguidores de Cristo de auxiliarem os pobres e os marginalizados na sociedade, já o Evangelho, não semiótico, de João, a missão de todos com Jesus Cristo permitiriam o desenvolvimento do puro afeto na Terra. Todas as ideias que seguem a linha de raciocínio bíblica (Antigo e Novo Testamento na visão cristã) são consideradas ideológicas do Cristianismo, e, formadoras das diversas éticas e morais das sociedades capitalistas, essas serão analisadas e justificadas, como esta alegação, a seguir.

As discrições das missões cristãs geralmente são especificadas e justificadas pelos seus meios e fins, segundo Medeiros (2016), na Teologia da Missão de René Padilla, o atingir o Reino de Deus se torna a primeira e a última realidade das ordens de Deus pela figura de Jesus Cristo, assim o declarar e buscar o reino de Deus com todos os seres humanos é a mediata (medidas das ações divinas, associadas as ordenanças da Igreja) da missão de todos os cristãos.

As diferenças dos cristãos que realizam as missões integrais são que eles vivem para levar o evangelho (no presente trabalho compreendido como todos os ensinamentos de Jesus Cristo para uma vida eterna) em todas as suas funções sociais; segundo Holz (2015), os missionários integrais têm como sentido primário glorificar o reino de deus e as outras funções são relacionadas ao possibilitar essa glorificação a partir dos desenvolvimentos saudáveis das Igrejas. Já a crítica resumida de Holz (2015) é:

Esta igreja relevante, que cumpre com a sua missão, que faz acontecer e que leva as pessoas 
a se aproximarem de Deus, aparentemente tem desaparecido. É notável o importante e imprescindível papel do líder que fará com que a teologia da missão integral seja observada. Deus levanta estes servos e os capacita. É necessário se manter atento ao que o Senhor deseja fazer, motivar o aperfeiçoamento dos dons e aplicação deles. (HOLZ, 2015)

Segundo Bosch (2002), desde o início do século XXI, os conceitos de missões se popularizaram entre os cristãos, entretanto o Cristianismo em geral vive sempre alimentado pela crise nas estruturas gerais das sociedades; agora a crise mais ampla é que os ensinamentos de Deus estão em decadência, aparentemente, para o "secularismo" e as "descrenças". Quais relações as práticas missionárias devem buscar?. Certamente as ligadas ao Amor de Deus, porquê todas as várias escrituras sagradas do mundo (Bíblia, Al Corão, Escritos de Buda) reflete o que a Bíblia deixa como verdade absoluta para seus fiéis, 'Deus é Amor'.

\section{DISCUSSÃO TEÓRICA}

\section{Cosmovisão da bíblia dos missionários cristãos atuais}

Para facilitar a interpretação, dividem-se, no presente trabalho, os missionários cristãos em três grandes estereótipos (relativo aos perfis comportamentais sociais), o Missionário Integral (o qual vive para missões religiosas); o Missionário parcial (aquele que vive na sociedade mais vinculado diretamente a alguma instituição religiosa, geralmente à atividade religiosa é secundária ao trabalho); o Missionário social (estuda religião de forma livre, desvinculado da Igreja, entretanto vive doutrinado no Cristianismo). "A cosmovisão cristã estava em um processo de mudanças fundamentais. De uma religião de contracultura, o cristianismo passou a ser uma religião portada pela cultura" (PADILLA, 1998). Através das visões culturais de René Padilla, que se fundamenta nas religiões cristãs da América latina, contudo não relata que as pequenas religiões da nova era e os cristãos sem religião, em partes, representa uma contracultura a sociedade atual, tendo algumas fundamentadas na Bíblia cristã, ou, em alguns textos bíblicos.

No Brasil o principal movimento religioso da nova era é a religião Espírita. "Já ao se falar de hibridismo religioso, podemos compreender o que acontece na chegada do espiritismo no Brasil e as intencionalidades que envolvem os processos de hibridização destas religiões" (QUEIROZ, 2019). Ao compreender a hibridização das religiões no Brasil, também se percebe o processo de contracultura nas tradições religiosas, donde antes o dogma de não falar com os mortos, principalmente das religiões mais antigas no Brasil, a Católica Apostólica Romana e o Protestantismo (adquire diversas doutrinas diferentes, intituladas pelos brasileiros de Evangélicas), recebem novas interpretações, os exemplos seriam: os espíritas falam com os espíritos desencarnados; os evangélicos se comunicam diretamente com o Espírito Santo e os seus métodos diferentes; os católicos com os santos e os anjos; todos esses exemplos são reformas nas interpretações bíblicas forçadas pelas novas compreensões da bíblia com intuito de manter seus fiéis nos determinados grandes corpos das Igrejas cristãs (o presente trabalho considera os maiores corpos: os católicos; os evangélicos e os espíritas, respectivamente em números de representatividades no senso comum do Brasil). Toda hibridização tradicional citada já foi consolidada na consciência popular brasileira.

De acordo com Medeiros (2016), uma ideia geral da Teologia de René Padilla pode relatar que a missão da Igreja é apenas uma extensão do corpo de Cristo (relativo aos fiéis que seguem os ensinamentos 
de Jesus Cristo), talvez ele esqueça das obras cristãs, como um pilar da missão da Igreja e da doutrina cristã, esta não como obra dos ensinamentos de Jesus Cristo, mas como obra do sacrifício de Jesus Cristo pela humanidade.

É na realização da missão que a experimentação deste fruto do reino vindouro promovido pelo Espírito ocorrerá tanto no meio da palavra e da ação, de maneira indissociável. Podese ilustrar essa compreensão de Padilla como no que ocorre em um voo. Os passageiros experimentam voar em um avião, que seria a igreja, como se pássaros fossem. E este avião só consegue alçar voo se estiver com duas asas (a palavra e a ação). Não há como a aviação proporcionar aos passageiros a experimentação de voar sem uma das asas. (MEDEIROS, 2016)

Por certo, as missões dos cristãos devem ser perfeitas como Deus, ou, como um grande avião, 'as duas asas são: as Escrituras Sagradas e as ações para Deus', entretanto falta uma cabine de comandos, que é a Liderança religiosa, por sua vez, comanda 'as asas' através da liberação de recursos para missões e as instruções mais sábias possíveis. Agora no Brasil e nos países latino-americanos, os recursos das religiões são limitados, pois suas economias e seus avanços tecnológicos, como também seus conhecimentos científicos, não são ditos como desenvolvidos.

Em geral, independente da forma de vivências dos seres humanos, buscar a simplicidade de viver como Jesus Cristo e atingir sua razão com toda natureza da Terra, é engrandecedor. Segundo Bosh (2002), a fé em Cristo torna possível uma comunhão com todos, as diferenças sociais não devem ser barreiras de interação entre todos os cristãos. "É isso que a missão paulina intenta realizar. A Igreja é chamada a ser a comunidade das pessoas que glorificam a Deus anunciando sua natureza e suas obras e tornando manifestas a reconciliação e a redenção que ele operou através da morte, ressurreição e reinado de cristo (cf. 1 Co 5.1820)" (BOSH, 2002). O sentido que se observa, para todas as Teologias e para as crenças religiosas, é a ampliação dos pensamentos, as verdades não devem ser nem dogmáticas e nem conhecimentos científicos absolutos.

É preciso que a racionalidade se amplie. Uma forma de realizá-lo é reconhecer que a linguagem não pode ser absolutamente exata, que, enfim não é possível "definir" nem leis científicas nem verdades teológicas. (BOSH, 2002)

O que acontece é que as verdades das missões religiosas não podem ser operacionalizadas, ou seja, o fiel não pode ser missionário de verdades teológicas preestabelecidas de suas Igrejas e nem racionalizar que a única fé correta é de sua religião. Hoje as religiões estão sendo reconstruídas pelos seus fiéis, em todos os sentidos, esse que antes era replicador de rituais, agora eles criaram seus próprios métodos de se comunicar com Deus. As missões são livres, muitos precisam está o tempo todo imersos as suas crenças, como também muitos apenas precisam de poucos minutos do dia para fortalecer sua fé em Deus.

Metáfora, símbolo, ritual, sinal e mito, desde longa data caluniados pelas pessoas que se interessam unicamente por expressões "exatas" da racionalidade, hoje em dia estão sendo reabilitados; eles criam formas que "sintetizam e evocam a integração de mente e vontade"; "não só tocam a mente e as suas concepções e evocam ação com um propósito, mas também compelem o coração". [...]. Assim, vemos rebrotar o interesse, especialmente em igrejas de Terceiro Mundo, pela "teologia narrativa", pela "teologia como estória" e por outras formas não-conceituais de teologizar. (BOSH, 2002)

Os discursos das missões cristãs têm vários desdobramentos em diferentes textos bíblicos e suas interpretações. O missionário cristão, e consequentemente suas missões, não pode ser considerado apenas 
aquele que vive inteiramente dependente a sua Igreja ou a sua doutrina religiosa.

Tendo em vista a sua missão, a igreja não deve ser neutra, passiva, indiferente e insensível aos problemas humanos. Ela não pode voltar a sua prática para dentro de si e nem considerar o seu campo de atuação apenas o campo sagrado. Ela não deve ser marcada pela falta de interação com a dinâmica da comunidade, isso quer dizer que ela deve ver os bairros da cidade como oportunidades para realizar uma ação. (VARGAS, 2014)

A partir das conclusões sobre as missões das Igrejas atuais, é nítido que a passividade da igreja frente aos problemas sociais de todos os cristãos (vinculados ou não a uma comunidade específica) afetam todos os seus fiéis. Como Jesus Cristo não pertencia a nenhuma Igreja judaica da época, os missionários não podem ficar presos a uma única igreja ou uma única doutrina cristã. Os discursos missionários precisam e sempre demostraram mais impactantes quando ligado diretamente a todos da sociedade, o melhor exemplo é o do messias Jesus Cristo.

Os diferentes aspectos das missões são explicados de diversas formas no mundo todo, mais seus principais objetos para os cristãos são sempre apresentados como o Falar de Deus (estudos teológicos aplicados aos diversos contextos) e com as Interpretações bíblicas (buscar viver através dos ensinamentos bíblicos nas sociedades atuais). Segundo Painadth (2013), toda teologia cristã se constrói de ter sua fé em Jesus Cristo, com base no Evangelho de Matheus a Igreja é a comunidade de todos os discípulos de Jesus Cristo.

Todos que se dizem Cristãos merecem ser membros de qualquer comunidade cristã, é a partir desta anunciação de relatar que é de Jesus Cristo que todos começam sua missão. O missionário social, segundo as análises anteriores, são todos que estão divididos entre as vivências sociais e as vivências religiosas. Já o missionário parcial, se determina por ter papéis sociais, considerados 'mundanos', mais ativo fielmente em sua comunidade cristã, muitos são até líderes religiosos. O missionário integral são todos que tem o papel religioso único e exclusivo para toda uma comunidade cristã determinada. O que se percebe é que todos têm seu papel social, dentro das características da missão religiosa.

\section{Transformação, conversão e espiritualidade}

Segundo Painadth (2013), viver com cristo é uma busca constante de aprender a lógica cristã (Cristologia) e uma busca de experiências espirituais com Jesus Cristo e Deus. Neste intuito, toda conversão, transformação ou vivência espiritual cristã se adquire através de missões religiosas que o fiel de quaisquer Igreja do Cristianismo, sejam elas em contextos sociais de forma racional, ou, em contextos sociais de forma de crenças ou de fé cristã.

Segundo Bosh (2002), para os teólogos não existe dúvida que o evangelho de Jesus Cristo e suas interpretações pelos apóstolos evangelistas, relatados na Bíblia, são para os pobres. Agora o termo "pobre" é relativo, nas sociedades capitalistas todos são pobres em algo. Em uma visão generalista, todos são pobres nas sociedades atuais, no senso comum brasileiro dizem: "Ou somos pobres de alma ou somos pobre de dinheiro"; apesar de ser determinista essa alegação, se conclui que o "sentir a pobreza" para o cristão é interpretativo e individual. O motivo principal das boas novas de Jesus Cristo na Bíblia é anunciar que todos podem fazer parte do 'Reino dos céus', desde que aceite viver com os ensinamentos de Jesus Cristo; aparenta 
se o cristianismo não for aberto para todos, com a teologia da missão, os missionários entram em guerras já perdidas para com Jesus Cristo.

Ainda assim, a conversão pessoal não é um alvo em si mesma. Interpretar a obra da igreja como "conquista de almas" significa tornar a conversão um produto final, o que contradiz terminantemente a compreensão lucana da finalidade da missão. [...]. A conversão não diz meramente a um ato de convicção e compromisso por parte de um indivíduo; ela coloca o indivíduo crente na comunidade dos crentes e implica em uma mudança real- e até radicalna vida do crente, que acarreta responsabilidades morais que distinguem os cristãos de "pessoas de fora" e, ao mesmo tempo, acentua sua obrigação para com essas "pessoas de fora" [...]. (BOSH, 2002)

Através de análise da missão no novo milênio, todos os processos missionários se trata do cristão ter todo um compromisso com os ensinamentos de Jesus Cristo, em todo os fatos da vida, tanto com os seus irmãos cristãos como seus irmãos não-cristãos próximos.

\section{Evangelização, missão e secularização}

Hoje se percebe que antigas tradições religiosas e culturais entram em conflito com a liberdade de informação e de pensamento que os Homens adquirem com os avanços das tecnologias digitais, entretanto difere a globalização com a secularização do pensamento religioso na atualidade. Segundo Ratzinger (2008), as várias teorias de crenças não adquirem muitas lógicas, e com estas teorias fica, cada vez mais, difícil a compreensão das Escrituras Sagradas; assim, antes mesmo da consolidação do termo "secularização", este já conceitua, então:

Devemos, portanto, dizer: o pluralismo da desintegração surge quando deixamos de sentirnos à altura da grande tensão interior do conjunto de Fé. Ele sempre pressupõe um estreitamento e empobrecimento, que diminui com a proliferação dos cristianismos parciais que se manifestam um ao lado do outro e um após outro; pelo contrário, só dessa maneira é que se manifesta a pobreza das tentativas isoladas. (RATZINGER, 2008)

Os conflitos das ideologias do Cristianismo é claro, pela teologia da missão, se resume em uma tricotomia de problemas ideológicos antagônicos, são: os cristianismos tradicionais; os cristianismos secularizados; os cristianismos racionalizados. Um cristianismo tradicional é aquele que considera a tradição a cima dos ideais cristãos. Os cristianismos secularizados são aqueles que descaracterizam as Escrituras Sagradas como o maior livro de ensinamentos do Cristianismo, em geral, muitas linhas de pensamentos cristãos que surgem na atualidade e são deixadas se influenciar pelos pensamentos modernos limitados, que se identificam com os pensamentos atuais sem bases lógicas dos estudos teológicos e dos estudos científicos. E um cristianismo racionalizado é aquele que descaracterizam os aspectos emocionais humanos, e, ou aspectos da natureza primitiva dos seres humanos. Aponta Padilla (1998): “O ponto de partida do estudo de participação dos laicos na missão cristã se encontra, nas atitudes, ensinamentos e ações de Jesus Cristo sempre". Portanto, se alguma ideologia relativa ou censura ideias do Cristianismo, foge de todos os ensinamentos de Jesus Cristo, em menor ou maior grau.

\section{Práticas cristãs atuais e fundamentos bíblicos}

As práticas cristãs atuais refletem as interpretações bíblicas que os cristãos adquirem na atualidade. 
A Bíblia sempre foi no popular cristão, o guia de vida na Terra para todos que desejam a vida eterna com Cristo, e, sem dúvida todos os estudiosos da bíblia e do Cristianismo, em geral, sabe que os textos bíblicos moldaram muitos aspectos populares da humanidade, em específico os países do ocidente, considerados predominantemente cristãos.

Segundo Ott et al. (2010), a Bíblia é o livro das missões cristãs e um guia atual de vida cristã; ainda de acordo com os escritos bíblicos e esse autor, Deus está trabalhando o tempo todo para a redenção de todos os povos. O que está claro na História do Cristianismo e na formação da Bíblia, que o melhor período de vida para todos será um reino de benevolências comum a todos os seres vivos, talvez utópico para o contexto da realidade atual; entretanto seu sonhar permite inúmeras bondades na Terra e a continuação das missões cristãs para esse reino. "O fracasso total dos esforços humanos para restaurar os relacionamentos quebrados com Deus, superam os efeitos do pecado e manifestam narrativas abertas" (OTT et al., 2010).

Várias são as tentativas de categorizar e de organizar o 'Falar de Deus', na modernidade, dos cristãos; contudo, todas as novas interpretações do 'Falar de Deus' se apresentam ideológicas por determinadas igrejas ou estudos teológicos; até o presente trabalho, possa se configurar em ideologias ecumênicas, embora cristãs. E apenas a Bíblia, para os cristãos, continua a representar o 'Falar de Deus', sem ideias preconcebidas de determinadas linhas e pensamentos corruptíveis humanos.

Vamos resumir o que descobrimos de nossa pesquisa sobre os ensinamentos do Antigo Testamento em missão, com referência particular a Deus e às nações:

1. Deus é o Criador de todos e soberano Senhor sobre todos os povos e todas as nações.

2. Embora todos os humanos tenham se rebelado contra o governo de Deus, Deus em sua graça tomou a iniciativa de fornecer um caminho de reconciliação, trazendo-os de volta ao seu reino.

3. Como resultado do chamado de Deus de Abraão e Israel, eles não eram apenas para serem abençoados, mas também para se tornarem uma bênção, mediando a justiça, a glória e a salvação de Deus para as nações.

4. A principal forma de testemunho de Israel era viver em retidão e adorar de todo o seu coração, manifestando assim o reino de Deus no meio das nações.

5. Israel deveria proclamar a salvação do Senhor no meio das nações e convidá-los a vir e adorar seu Senhor e adorar ele sozinho.

6. Israel falhou em sua missão como "luz das nações", mas o Messias iria cumprir esse papel, criar um novo povo do reino e enviá-los como suas testemunhas para as nações.

7. O dia viria quando Gentios de todas as nações adorassem o Senhor e ser incluído no povo do seu reino. Sião é representado como o ponto central para o qual as nações fluem.

8. Deus um dia julgará todas as nações, destruirá todo o mal e estabelecerá plenamente seu reino de paz e justiça sobre toda sua criação. (OTT et al., 2010)

A Bíblia, sobretudo o Antigo Testamento, mostra o reflexo dos homens destruindo toda a Terra, mais mesmo assim, Deus tem misericórdia dos homens e impedem sua autodestruição como humanidade. "Isto será revelado no Novo Testamento como uma revolução dramática: a formação de um povo do novo reino por Deus para trazer essa visão à realização" (OTT et al., 2010).

Os seres humanos criam 'grandes dramas de vida', mais os textos bíblicos dizem: 'vocês não sabem viver'; os homens insistentes e admirados com suas razões de vidas, dizem: 'somos mais que toda a natureza da Terra'; agora, acontece que todos dotados de consciência, 'não dão razão a consciência e destroem suas 
vidas naturais'. O que diz a Bíblia e Jesus Cristo: 'Os frutos dos desejos da tua alma foi-se de ti, e nunca mais voltarás' (Bíblia: Livro do Apocalipse, Capítulo 18, versículo 14).

\section{CONCLUSÕES}

O que a bíblia e Jesus Cristo diz? Dicens: 'Vade ad populum istum et dic: Auditu audietis et non intellegetis, et videntes videbitis et non perspicietis'. (Bíblia: Livro de Atos, Capítulo 28, versículo 26. Tradução em Latim). A tradução do Latim para o português, pode ser: 'Dizendo: Ir para a população e isto pode ser dito: pelo ouvir, ouvistes e não compreendeste, e vendo, vereis e não percebestes'. Neste trecho e em todo presente trabalho, se percebem, que a Bíblia e a teologia da missão, um retratar do Cristianismo como simples e verdadeiro, entretanto para aqueles que vivenciam as 'verdades cristãs' como um conjunto de saberes simplificados para todos os seres humanos, mesmo sem aderirem o Cristianismo através das Igrejas atuais. Umas determinadas interpretações duvidosas dos textos bíblicos, não podem fundamentar as missões cristãs para todos, mesmo hipoteticamente com a adesão global dos indivíduos sociais a uma determinada comunidade cristã.

Em síntese, a 'missiologia' não devem aderir as verdades absolutas, nem da ciência, nem das teologias, e, muito menos, de tradições. O que se reflete é uma teologia da missão com uma fundamentação histórica popular, sem vínculos aos saberes dos homens presos as civilizações modernas, ou seja, as estruturas missionárias cristãs, para constarem como efetivas e alinhadas aos textos bíblicos juntamente com os contextos sociais atuais, são necessárias missões ecumênicas, que adquiram características pluralistas, e que não se limitem as ideologias dominantes.

Por último, sobre os missionários e as suas crenças de fé, são completas se permitirem o livre acesso pelos modos de inteligências emocionais e de inteligências racionais, pois se houver a descaracterização de um desse conjunto de inteligências, os cristãos não adentraram na sabedoria de Deus eterna, assim como a vida eterna, relatada em tuas 'Escrituras Sagradas'.

\section{REFERÊNCIAS}

BOSCH, D. J.. Missão Transformadora: mudanças de paradigma na Teologia da Missão. São Leopoldo: EST Sinodal, 2002.

EMEDIATO, W.; FRANCO, E. A.. Discurso religioso, argumentação e cognição da fé. Dissertação (Mestrado em Estudos Linguísticos) - Universidade Federal de Minas Gerais, Belo Horizonte, 2017.

HOLZ, D.. Teologia da missão integral: uma proposta de cumprimento da grande missão de glorificar a deus. Revista Ensaios Teológicos, Brasília, v.1, n.1, 2015.

MEDEIROS, D. A. G.. O Reino de Deus e a Igreja na Teologia da Missão Integral de René Padilha. Dissertação (Mestrado) - Universidade Metodista de São Paulo, São Bernardo do Campo, 2016.
OTT, C.; STRAUSS, S. J.. Encountering theology of mission: biblical foundations, historical developments, and contemporary issues. Michigan: Backer Academic, 2010.

PADILLA, C. R.. Bases Bíblicas de la Misión. Buenos Aires: Nueva Criation, 1998.

PAINADATH, S.. Spiritualität und Christologie. Freiburg: HERDER, 2013.

QUEIROZ, E. J.. Hibridismo religioso: as tradições católicas, afro-brasileiras e o espiritismo. Ponta Grossa: Atena, 2019.

RATZINGER, J. C.. Natureza e Missão da Teologia. Petrópolis: Vozes, 2008.

VARGAS, D. A.. Uma Breve Reflexão sobre a missão da Igreja cristã. Revista de Teologia da Faculdade FAIFA, Vox Faifae, v.6, n.3, p.1-18, 2014

A CBPC - Companhia Brasileira de Produção Científica (CNPJ: 11.221.422/0001-03) detém os direitos materiais desta publicação. Os direitos referem-se à publicação do trabalho em qualquer parte do mundo, incluindo os direitos às renovações, expansões e disseminações da contribuição, bem como outros direitos subsidiários. Todos os trabalhos publicados eletronicamente poderão posteriormente ser publicados em coletâneas impressas sob coordenação da Sustenere Publishing, da Companhia Brasileira de Produção Científica e seus parceiros autorizados. Os (as) autores (as) preservam os direitos autorais, mas não têm permissão para a publicação da contribuição em outro meio, impresso ou digital, em português ou em tradução. 